\title{
Creative Industries Development and Efficiency in China
}

\author{
Wentao Yu \\ Business School, Jiangsu Normal University, Jiangsu, China \\ Corresponding Email: zeroyu@mail.ustc.edu.cn
}

\begin{abstract}
China is becoming a leading player in the world market of creative goods and service. In this paper we first seek to explore the development and structure of urban creative industries in China. It indicates that China's city creative industries is fast increasing during the period of 2004-2008. Secondly, a Data Envelopment Analysis (DEA) model, based on the data of China's 36 capital and/or sub-provincial cities, is used to estimate the Technical Efficiency (TE) of urban creative industries, where the efficiency scores are decomposed into the Pure Technical Efficiency (PTE) and Scale Efficiency (SE). Due to poor input utilization and scale inefficiency, it shows most of cities in China are falling into the situation with low efficiency development on creative sectors. Finally, the paper provides some implications for policy makers on how to increase creative industries efficiency.
\end{abstract}

Keywords. Creative industries, technology efficiency, Data Envelopment Agreement (DEA).

\section{Introduction}

As our society moves into the so-called information age when the economic growth is greatly driven by innovation and creativity, the creative industries as one of most dynamic emerging sectors are growing rapidly and becoming a new engine of the world economic growth. UNCTAD (2010) shows that the world trade of creative goods and services continues its expansion in 2008 , reaching $\$ 592$ billion with an annual growth rate of 14 per cent during the period of 2002-2008, despite a decline of 12 per cent in global trade due to financial crisis. China has become a leading player in the world market for creative goods with an impressive 20 per cent exporting market share during the period from 2000 to 2008 (UNCTAD, 2010).

It is suggested creative industries is on the huge growth in the contemporary economy. Yusuf \& Nabeshima (2005) highlight the economic center of gravity of the leading cities is changing from manufacturing to creative industries. To lead growth and own comparative advantage, cities need to evolve or remain as the centers of creative industries or service-providing hubs. The existing studies show the development of creative industries or the creative class plays an increasing role in driving and facilitating regional wealth and employment growth (Asheim \& Hansen, 2009; Boschma \& Fritsch, 2009; Rumpel et al., 2010; Cooke \& De Propris, 2011). Creative industries rely on various factors, such as word of mouth, taste, culture, and popularity, in which individual choices are dominated by information feedback over social networks rather than innate preferences and price signals (Potts et al., 2008). Therefore, the creative industries should be explored by multidisciplinary approach (Pratt, 2013; Andres \& Chapain, 2013; Kacerauskas, 2013), rather than only by case study or policy science perspective. Kacerauskas (2013) argues the analysis on creative and cultural industries should refer to philosophical, sociological and communication aspects. However, recent research lacks of paying attention to the 
growth of creative industries efficiency. As a result the efficiency score of the creative industries at the regional level or sector level is still under explored, particularly in China.

In this paper we attempt to respond to the existing unexplained questions and verify: how much efficiency scores does the creative industries achieve in China. Based on the data of China's 36 capital and/or sub-provincial cities, a data envelopment analysis (DEA) model is applied to assess technology efficiency of China's city creative industries (including pure technical efficiency and scale efficiency). The results show the technology efficiency score of urban creative industries is $58.3 \%$ during the period of 2002-2008 in China, including pure technical efficiency score of $66.3 \%$ and scale efficiency score of $89.3 \%$. In general, due to poor input utilization and scale inefficiency, it shows most of cities in China are falling into the situation with low efficiency development on creative groups. This study not only can be helpful to understand problems hiding in China's creative industries despite of its fast growing but also provides a representative case for the world creative industries development from the biggest developing country in China.

The development structure of creative industries in China is depicted in the following section (Section 2). China's CIA at the city level is discussed in Section 3. China's city creative industries efficiency is estimated and analyzed in Section 4. The last section is the conclusions.

\section{The development of creative industries in china}

The participation in global markets for producing creative goods and services is extremely strong in the advanced economies. In recent years the rise of the creative industries are unprecedented in speed and scale in the developing economies, particularly in China. China is becoming a leading player in the world trade of creative goods, accounting for 20 per cent of world market. In 2008 China is turned out to be the largest trade surplus in creative goods with net exports of 79 billion, while the United States has the largest trade deficits in creative goods with net imports of 55 billion (UNCTAD, 2010).

Table 1 presents the development of China's creative industries compared to the general industry during the period of 2004-2008. The trend growth rate of the number of creative firm is calculated to be close to $20.11 \%$ per year while the growth rate of new firm in general industries appears to be $13.16 \%$ a year throughout the period of 2004-2008. The employment in the creative sectors grows $11.97 \%$ per year over $2004-2008$, compared to $7.78 \%$ of employment growth for general industries. In 2008 the creative industries produced 4648.64 billion yuan in operating revenue with an average annual growth rate (AAGR) of $25.71 \%$ for $2004-2008$, in contrast, the annual growth rate of operating revenue reach up to $34.05 \%$ in general industries.

Table 1. The development of creative industries in China.

\begin{tabular}{l|l|c|c|c}
\hline Category & \multicolumn{1}{|c|}{ Industry } & $\mathbf{2 0 0 4}$ & $\mathbf{2 0 0 8}$ & AAGR (\%) \\
\hline \multirow{4}{*}{ The number of firms } & Creative industries (CI) (1000) & 378.96 & 683.78 & 20.11 \\
& General industries (GI) (1000) & 3249.34 & 4959.67 & 13.16 \\
& The share of CI in GI (\%) & 11.66 & 13.79 & 4.55 \\
\hline \multirow{3}{*}{ Employ-ment } & Creative industries (million workers) & 9.43 & 13.94 & 11.97 \\
& General industries (million workers) & 166.93 & 218.89 & 7.78 \\
& The share of CI in GI (\%) & 5.65 & 6.37 & 3.19 \\
\hline \multirow{3}{*}{ Income } & Creative industries (in billion of RMB) & 2291.66 & 4648.64 & 25.71 \\
& General industries (in billion of RMB) & 44097.65 & 104167.2 & 34.05 \\
& \multicolumn{2}{|c}{4.46} & -3.53 \\
\hline
\end{tabular}

Source: Author's calculations based on the China Economic Census Yearbook (2010). 
In 2008 there are 683781 creative firms registered in China, accounting for $13.79 \%$ in all registered firms, while the employment of creative industries is 13.94 million yuan, accounting for $6.37 \%$ of all employment in China. The revenue generated by creative firms is 4648.64 billion yuan, but accounting for $4.46 \%$ only of all industries revenue. It shows the proportion of business income of the creative industries in all industries revenue (i.e. $4.46 \%$ ) is slightly less than the share of creative employment in total employment (i.e. 6.37\%), but considerably less than the ratio of creative firm in all firms (i.e. 13.79\%). It indicates that the average size of creative firms is slightly smaller than other firms, and the development of business incomes in creative industries is lagged behind general industries probably due to productivity shortfalls.

Data for the share of creative industries in general industries illustrated in Table 1 indicates that 13.79 per cent creative firms produce 6.37 per cent creative employments but only generate 4.46 per cent revenue incomes in all industries in 2008. Table 1 also shows a negative score $(-3.53 \%)$ of the AAGR on operating revenue of creative industries during the period of 2004-2008, while the creative firms and employments are both highly increased by $4.55 \%$ and $3.19 \%$ respectively per year over the same period. In other words, it inputs the same creative firms and employments but outputs less incomes, implying there is serious inequality between the inputs and outputs of China's creative industries.

It is inferred that China's creative industries may fall into low efficiency by the observation that the share of creative industries revenue in total revenue is much less than the proportion of creative employment in total employment as revealed in Table 1. However, this argument may suffer from a suspicion because there is not sufficient empirical evidence to calculate how inefficient is the creative industries in China. To deal with this suspicion, empirically, the efficiency of creative industries by different sectors and regions will be estimated in Section 3.

\section{China's city creative industries efficiency}

Data envelopment analysis (DEA) is a mathematical programming approach to provide a relative efficiency assessment for a group of decision making units (DMU) by the ratio of inputs and outputs. Determining whether a DMU is efficient from the observed data is equivalent to testing whether the DMU is on the "frontier" of the production possibility set (Wei, 2000). In this paper, the variable returns to scale (VRS) model of DEA is used to calculate city efficiency of creative industries in China, where the VRS model allows breaking technical efficiency (TE) into two components: pure technical efficiency (PTE) and scale efficiency (SE). The PTE measures how a DMU utilizes the resources under exogenous environments, while the SE is the potential productivity gain from achieving optimal size of a firm (Wei, 2000).

Table 2. Summary statistics for the input and output data.

\begin{tabular}{c|l|l|l}
\hline \multicolumn{1}{c|}{ Inputs } & Unit & Mean & St. dv. \\
\hline $\begin{array}{c}\text { Employment of creative } \\
\text { industries }\end{array}$ & $\begin{array}{l}\text { No. of } \\
\text { workers }\end{array}$ & $\begin{array}{l}27571 \\
1\end{array}$ & 353687 \\
\hline $\begin{array}{c}\text { Total asset of creative } \\
\text { industries }\end{array}$ & $\begin{array}{l}10 \text { billion } \\
\text { Yuan }\end{array}$ & 492.40 & 995.19 \\
\hline Output & Unit & Mean & St. dv. \\
\hline $\begin{array}{c}\text { Operating revenue of } \\
\text { creative industries }\end{array}$ & $\begin{array}{l}10 \text { billion } \\
\text { Yuan }\end{array}$ & 93.30 & 169.28 \\
\hline
\end{tabular}

Source: Author's calculations based on the China Economic Census Yearbook (2010).

The input and output variables selected should be best representative quality in estimating the efficiency. The DEA model, in this paper, includes two inputs and a single output. The output corresponds to the operating revenue of creative industries, while the input is measured by creative employment and total asset of creative industries. The data of inputs and output based on China's 36 capital and/or sub-capital cities all are from China Economic Census Yearbook (National Bureau of Statistic of China, 2010). Input and output variables have been identified in Table 2.

Table 3 presents the TE, PTE and SE scores of creative industries of top 10 and bottom 10 selected cities in 2008. On average, the technical efficiency score of China's creative industries is $58 \%$ in 2008 , indicating $42 \%$ of efficiency has 
been lost. There are 15 cities (accounting for $42 \%$ of the sample) whose efficiency scores of creative industries have exceeded $60 \%$ (see Table 3). Nanchang and Urumchi being with TE scores of $100 \%$ are on the "frontier" of the production, suggesting these two cities have achieved the point of best relative efficiency in creative sectors, while Xining is found to be the least efficient relatively with TE scores of $27 \%$. The TE score of top 10 cities are turned out to be more than $70 \%$, in which 8 out of 10 cities, i.e. Urumchi, Nanchang, Beijing, Xi-an, Guangzhou, Shanghai, Chengdu and Lhasa are fully efficient on PTE score.

Table 3. Efficiency scores in urban China.

\begin{tabular}{cccc}
\hline Top10 cities & Technical efficiency & Pure technical efficiency & Scale efficiency \\
\hline Nanchang & 1 & 1 & 1 \\
Urumchi & 1 & 1 & 1 \\
Beijing & 0.892 & 1 & 0.892 \\
Changchun & 0.874 & 0.968 & 0.902 \\
Xi'an & 0.842 & 1 & 0.842 \\
Guangzhou & 0.811 & 1 & 0.811 \\
Shanghai & 0.790 & 1 & 0.790 \\
Chengdu & 0.757 & 1 & 0.757 \\
Jinan & 0.752 & 0.88 & 0.854 \\
Hohhot & 0.749 & 0.763 & 0.981 \\
\hline Bottom 10 cities & Technical efficiency & Pure technical efficiency & Scale efficiency \\
\hline Wuhan & 0.451 & 0.487 & 0.926 \\
Nanning & 0.442 & 0.451 & 0.980 \\
Harbin & 0.439 & 0.439 & 0.999 \\
Shenyang & 0.423 & 0.428 & 0.989 \\
Yinchuan & 0.394 & 0.487 & 0.809 \\
Guiyang & 0.366 & 0.423 & 0.865 \\
Tianjin & 0.358 & 0.374 & 0.958 \\
Lanzhou & 0.302 & 0.326 & 0.927 \\
Haikou & 0.298 & 0.382 & 0.780 \\
Xining & 0.270 & 0.438 & 0.616 \\
Mean & $\mathbf{0 . 5 8 3}$ & $\mathbf{0 . 6 6 3}$ & $\mathbf{0 . 8 9 3}$ \\
\hline & & & \\
\hline
\end{tabular}

The mean score of scale efficiency is calculated as being $89.3 \%$ in creative industries, which is slightly higher than its TE scores (58.3\%) and PTE scores (66.3\%). In 2008, 30 out of 36 cities (approximately accounting for $83 \%$ of the sample) whose scale efficiency scores have exceeded $80 \%$. However, 22 out of 36 cities (accounting for $61 \%$ of the sample) exhibit decreasing returns to scale on the production frontier of creative industries, implying the size of creative firm in those cities are engaged in production on a non-optimal scale. Alternatively, it may be a good way to increase their efficiency of creative industries by optimizing the size of creative firm appropriately.

If the cities aim to increase their technology efficiency of creative industries, both the PTE and SE should be paid attention to. Table 3 shows that some cities such as Lanzhou and Tianjin are calculated as low TE scores due to extremely PTE scores although they possess relatively high SE scores. In contrast, Zhengzhou is on the best efficient of scale, but its PTE score is only 48.2 per cent, leading to a relatively low technical efficiency.

Table 4. Efficiency scores estimated by creative sub-sectors

\section{Creative sub-sectors}

Technical efficiency Pure technical efficiency Scale efficiency
0.689

Software and computer services

0.689

0.758

0.911 


\begin{tabular}{clll} 
Design & 0.685 & 0.790 & 0.871 \\
Performing arts and publishing & 0.613 & 0.655 & 0.938 \\
Leisure and Entertainment & 0.572 & 0.666 & 0.858 \\
Audio visuals & 0.500 & 0.618 & 0.813 \\
Creative R\&D & 0.396 & 0.474 & 0.879 \\
Crafts and fashion & 0.372 & 0.545 & 0.703 \\
Advertising & 0.301 & 0.406 & 0.830 \\
Mean of creative sectors & 0.583 & 0.663 & 0.893 \\
\hline
\end{tabular}

Notes: Audio visuals include film, music, television and radio.

Table 4 presents the efficiency scores of creative industries by sub-sectors. It shows that China's software industry owns the highest technical efficiency scores (i.e. 68.9\%), including PTE scores of $75.8 \%$ and SE scores of $91.1 \%$ in 2008. It is suggested the software industry has been growing rapidly and effectively over the last decades in China and boosts economic growth significantly (Yang et al., 2005), resulting in a higher technical efficiency. The TE scores of designing service $(68.5 \%)$ and performing arts \& publishing (61.3\%) are found to be more than the average level (58.3\%), while advertising is being on the least inefficient with TE score of $30.1 \%$ out of 8 creative sectors.

In summary, China's creative industries is experiencing tremendous growth over the world, but its productive efficiency and the ability to create business profit still have a big increasing room.

\section{Conclusion}

This paper, first explores the development and structure of China's creative industries, including the growth and development of the number of creative firm, creative employment and operating revenue. This exploration implies that China's creative industries is at the low efficiency level despite fast development. The DEA model, based on the data of China's 36 capital and/or sub-provincial cities, is used to investigate technology efficiency of China's city creative industries (including pure technical efficiency and scale efficiency). The empirical result shows the technology efficiency (particular in pure technology efficiency) of China's city creative industries is indeed relatively low. On average, the technical efficiency score of China's creative industries is estimated to be $58 \%$ in 2008 . We suggest, on the one hand, the development of clustering of smaller creative firms is becoming an effective way to boost its efficiency, because most of cities in China now exhibit decreasing returns to scale on creative industries productivity. On the other hand, the pure technology efficiency of the creative groups should be much more increased by applying more new technologies and new business mode.

\section{Acknowledgements}

The author wants to acknowledge the support of the Natural Science Foundation of Jiangsu Province (No. BK20150234), and the Social Science Foundation of Jiangsu Province (No. 14EYC004).

\section{References}

1. UNCTAD, 2010, Creative Economy. Report 2008. UNDP, UNCTAD, Geneva New York. [R/OL]. http://unctad.org/en/Docs/ditctab20103_en.pdf. UNDP \& UNCTAD, Geneva.

2. Yusuf S, Nabeshima K., 2005, Creative industries in east Asia. Cities, 22(2): 109-122.

3. Rumpel P, Slach O, Koutský J. 2010. Creative industries in spatial perspective in the old industrial Moravian-Silesian region. E+M Ekonomie a Management, 8(4): 30-46.

4. Asheim B T, Hansen H K. 2009. Knowledge Bases, Talents and Contexts: On the Usefulness of the Creative Class Approach in Sweden. Economic Geography, 85(4): 425-442. 
5. Boschma R A, Fritsch M. 2009. Creative class and regional growth: empirical evidence from seven European countries. Economic Geography, 85(4): 391-423.

6. Cooke P, De Propris L. 2011. A policy agenda for EU smart growth: the role of creative and cultural industries. Policy Studies, 32(4): 365-375.

7. Potts J, Cunningham S. 2008. Four models of the creative industries. International Journal of Cultural Policy, 14(3): 233-247.

8. Pratt A C. 2004. Creative clusters: Towards the governance of the creative industries production system? Media International Australia, 112(1): 50-66.

9. Wei Q. 2000. Effective methods on evaluating relative efficiency (DEA). Chinese Science Bulletin, 45(17):1793-1807.

10. National Bureau of Statistics of China. 2009. China Statistical Yearbook (2010). China Statistics Press, Beijing.

11. Andres, L., Caroline C.2013. The integration of cultural and creative industries into local and regional development strategies in Birmingham and Marseille: towards an inclusive and collaborative governance? Regional Studies, 47(2): 161-182.

12. Kacerauskas, T. 2013. Creative and cultural industries: philosophical, sociological and communication aspects. FILOSOFIJA-SOCIOLOGIJA, 24(3): 112-120. 